\title{
DECLARACIÓN DE GOBIERNO \\ DEL CANCILLER FEDERAL, DR. HELMUT KOHL, ANTE EL PLENO DEL BUNDESTAG ALEMÁN EL 10 DE MAYO DE 1990
}





\section{DECLARACIÓN DE GOBIERNO DEL CANCILLER FEDERAL, DR. HELMUT KOHL, ANTE EL PLENO DEL BUNDESTAG ALEMÁN EL 10 DE MAYO DE 1990}

\section{Señor Presidente, Señoras y Señores:}

"Una Alemania libre y unida en una Europa libre y unida». Esta visión de Konrad Adenauer se ha hecho palpable en estos momentos. Constituye el leitmotiv de nuestra política. Hoy podemos hacer constar: Durante las últimas semanas hemos hecho buenos progresos en la senda hacia este objetivo. Esto vale tanto para la regulación de los aspectos exteriores del proceso de unificación como también para las negociaciones que actualmente se están llevando a cabo con la RDA.

Desde el principio ha sido la aspiración del Gobierno Federal tener siempre en cuenta que el proceso de la unidad alemana se inserte en un sólido marco europeo. Esto significa también promover estos dos procesos en la medida de lo posible en armonía entre si y en estrecha coordjnación con todos nuestros socios y aliados.

La primera reunión de los Ministros de Relaciones Exteriores en el marco de las conversaciones "Dos más Cuatro" celebrada el 5 de mayo en Bonn, sobre la que el Ministro Federal de Relaciones Exteriores informará a Vds. a continuación, así como la cumbre de la Comunidad Europea celebrada el 28 de abril en Dublín, han iniciado una nueva fase muy importante. En Dublín nuestros socios de la CE se han manifestado de manera unánime y sin reservas en pro de la unidad alemana. Ellos apoyan el camino por el cual los alemanes van ahora. Éste es un motivo para estar agradecidos. Mi agradecimiento especial se dirige a los miembros de la Comisión de la CE, y ante todo al Presidente, Jacques Delors. Lo quiero decir de una manera muy personal: una vez más, Jacques Delors se ha acreditado como amigo de nuestro país. Juntamente con sus colegas de la Comisión, ha hecho un aporte decisivo a que se hayan podido indicar caminos adecuados para la inclusión de la RDA en la Comunidad Europea. 
Señoras y señores, en Dublín hemos explicado a nuestros socios los problemas económicos y sociales que se nos avecinan con los enormes desafíos relacionados con la creación de la unidad de Alemania. Una y otra vez he subrayado - y me parece importante decirlo también aquíque no queremos solucionar estos problemas -tampoco los problemas económico-financieros que nadie quiere desconocer- a costa de otros miembros en la CE. Nuestra meta debe ser la siguiente: unidad alemana y unidad europea. Sería un mal servicio para el futuro de Europa si los países de la Comunidad Europea con estructuras débiles tuvieran que atrasar ahora su desarrollo en vez de avanzar en la senda del ajuste de sus estructuras, porque en estos momentos se convierte en realidad la oportunidad para más libertad en el centro, en el este y en el sudeste de Europa $y$, desde luego, también en la RDA. Queremos ejercer un influjo positivo sobre el desarrollo en el centro, el este y en el sudeste de Europa y crear también la unidad alemana con todo lo que forme parte de ella, pero queremos impedir al mismo tiempo que se abra aún más la tenaza del desarrollo de los diversos Estados de la Comunidad Europea. Al contrario, los desarrollos deben ajustarse paulatinamente.

Permitanme subrayar: para nosotros como alemanes, para el desarrollo en la RDA y para el proceso de unificación en Alemania es importante que, juntamente con nuestros socios europeos en la Comunidad y ante todo también con la Comisión, encontremos arreglos y medidas de transición sensatos y sólidos, cuando se trate de la inclusión de la RDA en la Comunidad Europea. Sólo quiero mencionar dos ejemplos: piensen Vds. en las enormes dificultades en cuanto al ajuste de la política agrícola de la RDA con miras a la Comunidad Europea, o piensen por ejemplo en los desafíos que se plantean en el sector de la protección del medio ambiente. Aquí se trata de dos problemas que, dados los plazos necesarios, no podemos solucionar de manera satisfactoria sin la cooperación y la comprensión de nuestros socios en la Comunidad Europea.

Señoras y señores, la importancia de la cumbre de Dublín va sin embargo mucho más allá de la cuestión de la unidad alemana. Es manifiesto que el proceso de la unidad alemana se muestra como catalizador para la aceleración de la integración de Europa en la senda hacia la unión política. Promover Europa es también el objetivo de la iniciativa que el Presidente François Mitterrand y yo tomamos conjuntamente antes de esta cumbre. En Dublín tuvimos una primera discusión intensa sobre este tema. A partir del mes de diciembre del año en curso nos proponemos, con ocasión de dos conferencias intergubernamentales paralelas que se podrían inaugurar con motivo de la cumbre de la CE a fines del año 1990 en Roma, entrar en la deliberación de los elementos medulares de la ulterior integración de Europa. 
En este contexto se trata por una parte de la unión económica y monetaria sobre la base de las decisiones adoptadas en Estrasburgo en diciembre del año pasado. Por otra parte, se trata de la unión política, que según nuestro convencimiento ha sido desde el principio la meta fundamental de los Tratados de Roma y lo sigue siendo. Al mismo tiempo, debemos promover tenaz y decididamente la culminación del mercado único hasta el 31 de diciembre de 1992, de conformidad con los planes previstos. Nuestro objetivo es y debe ser poner en práctica estos tres proyectos fundamentales de reforma hasta fines de diciembre de 1992.

Permítanme tratar en este lugar unas pocas cuestiones fundamentales de la unión política:

Primero se trata del fortalecimiento de los derechos de control y de las competencias del Parlamento Europeo. Todos nosotros necesitamos progresos cuando en 1994 nos presentemos nuevamente a los electores en la República Federal de Alemania —al igual que en los demás Estados miembros de la Comunidad-para pedirles que voten mediante elecciones libres, secretas y directas el Parlamento Europeo. No creo que podamos volver a pedir de los electores que den su voto en favor de un Parlamento Europeo con tan pocas competencias como las que tiene ahora.

Menciono otro segundo argumento importante que seguramente corresponde a nuestra comprensión común de la democracia. Debería responder propiamente a nuestra autocomprensión parlamentaria que sólo podemos ceder más derechos de los parlamentos nacionales y también de los gobiernos a las instituciones europeas si se establece simultáneamente un claro control parlamentario también a nivel europeo.

En segundo lugar, se trata para nosotros de la consolidación de la unidad y de la coherencia de la Comunidad en todos sus campos políticos.

En tercer lugar, se trata de otros avances palpables en la senda hacia una política exterior y de seguridad común. Esto responde a los objetivos ya incluidos en el Acta Única Europea. Pero, señoras y señores, esto responde también a las urgentes necesidades del reto histórico para los europeos en los años noventa.

En cuarto lugar, se trata para nosotros de una mayor eficacia del trabajo de las instituciones comunitarias.

Señoras y señores, soy consciente de que en este campo tenemos que hacer frente a cuestiones sumamente delicadas y difíciles. Pero no 
debemos eludir estos problemas si en los próximos años queremos sentar las bases para la Unión Europea. Debemos hacer frente a este desafío si queremos que la Comunidad Europea como núcleo de Europa ocupe en el futuro el lugar que le compete según la comprensión de todos nosotros. Se trata de que la Comunidad haga justicia en el futuro a su creciente papel económico y ante todo también a su papel político. Eso se hace visible de manera especial en las relaciones de la Comunidad para con nuestros vecinos europeos, en especial con los Estados en el centro, el este y el sudeste de Europa que han iniciado reformas. Éste ha sido el tercer punto de nuestras deliberaciones de Dublín.

Esta cumbre extraordinaria ha puesto de relieve una vez más la responsabilidad y el empeño de la Comunidad por toda Europa. En los próximos años debemos hacer más densa la red de cooperación, tanto en el campo político como en el económico. No queremos marginar a nadie, al contrario: queremos que nuestros vecinos, ante todo en el centro, el este y el sudeste de Europa, se beneficien de la superación de la división de Europa tanto como nosotros. Porque Varsovia, Praga y Budapest forman parte de Europa al igual que París, Londres, Roma o Berlín.

Señoras y señores, la cumbre de Dublín ha demostrado que los Doce han reconocido los signos de la época. Por esta razón he calificado esta cumbre como momento histórico, no sólo para los alemanes sino para toda Europa. En el espíritu de Konrad Adenauer, la frase principal de los resultados de la cumbre de Dublin subraya: "Nos congratulamos de que la unidad alemana se realice bajo un techo europeo".

Señor Presidente, señoras y señores, el Consejo Europeo corrobora con ello que la unidad alemana y la unidad europea no se contradicen mutuamente, sino que son las dos caras de una misma moneda.

Señoras y señores, también en el proceso interior de la unificación alemana hemos conseguido un avance decisivo durante las últimas semanas. Después de intensas negociaciones nos pusimos de acuerdo con el Gobierno de la RDA sobre importantes datos básicos de la unión monetaria. Al hacerlo así, hemos cumplido con nuestra promesa de llegar hasta comienzos de mayo a un acuerdo sobre esta materia. Mientras tanto, existe también conformidad sobre partes esenciales de la unión económica y social, siendo evidente que en las intensas deliberaciones de estos dias hay una serie de puntos importantes que quedan por aclarar.

Ha quedado acordado lo siguiente: El 2 de julio la República Federal de Alemania y la RDA pondrán en práctica una unión monetaria, económica y social. Así, para las personas humanas en Alemania la unidad se convierte en realidad palpable en un sector decisivo. 
El resultado de las negociaciones se inspira en la consciencia de nuestra responsabilidad común por el futuro de Alemania y en especial por nuestros compatriotas en la RDA. Ellos pueden percibir ahora la perspectiva de que las regiones de la RDA muy pronto pueden convertirse en paisajes florecientes de una Alemania reunificada.

La introducción del marco occidental a comienzos del mes de julio es más que un signo de esperanza. Es un signo claramente perceptible de la solidaridad de todos los alemanes. De esta manera se vinculan indisolublemente el futuro de la República Federal de Alemania y el de la RDA.

En nuestras negociaciones nos hemos guiado por el objetivo -en el cual el Gobierno Federal y el Gobierno de la RDA están plenamente de acuerdo- de que debe asegurarse la estabilidad del marco occidental y que esto constituye también un objetivo decisivo de la futura política común. Porque a la larga el bienestar económico y la seguridad social sólo pueden basarse sobre una moneda estable.

Por eso redunda también en el bien entendido interés de nuestros compatriotas en la RDA que protejamos el marco occidental contra los riesgos inflacionistas Estoy convencido de que el resultado conseguido hasta ahora en las negociaciones tiene plenamente en cuenta este objetivo.

A la introducción del marco occidental juntamente con la unión económica y social se une al mismo tiempo la transición del "socialismo realmente existente», una economía planificada basada sobre órdenes superiores, a la economía social del mercado. Éste es un paso valiente $y$ al mismo tiempo singular. En este contexto no pierdo de vista de ninguna manera los riesgos y las imponderabilidades que conlleva un paso de esta índole. Pero estoy convencido $-y$ también en este punto estoy de acuerdo con el Presidente Lothar de Maizière- - de que sólo de esta manera haremos justicia a nuestra responsabilidad por las personas humanas en Alemania. Sólo así los alemanes en la RDA pueden obtener la convincente perspectiva de que sus condiciones de vida $y$ de empleo mejorarán visiblemente dentro de poco tiempo.

Con la introducción de la economía social del mercado se podrá desenvolver la fuerza de la libertad en provecho de las personas humanas. La disposición al rendimiento, la creatividad, el espíritu emprendedor se liberarán y en último término todos se beneficiarán de ello. En eso confiamos. Esto vale tanto para la RDA como hasta ahora ya para la República Federal de Alemania. Porque, con miras a alguna discusión que otra de los últimos días, séame permitido observar que durante 40 años 
se ha trabajado duramente por el bienestar de la República Federal y muchas personas en nuestro país han cooperado y siguen cooperando en este esfuerzo.

Señoras y señores, nos hemos puesto de acuerdo sobre los siguientes puntos: el Gobierno de la RDA y el Gobierno Federal concertarán un tratado sobre la introducción de la unión monetaria, económica y social. Dicho tratado entrará en vigor el 1 de julio de 1990.

Después de esta fecha, el 2 de julio el marco de la RDA se cambiará por el marco occidental, es decir, en el caso de los salarios, sueldos, becas, alquileres, arrendamientos y pensiones y otras jubilaciones periódicas el cambio será a la par. En cuanto a los salarios y sueldos, se toman como base los importes brutos del 1 de mayo de 1990. El sistema de pensiones de la RDA será adaptado al sistema de la República Federal de Alemania. Esto significa que el importe de la mayoría de las pensiones en marcos occidentales será más alto que el importe actual en marcos orientales. Si en casos individuales resultase un importe inferior en comparación con la pensión percibida hasta ahora en marcos de la RDA, se garantizará el pago en marcos occidentales de la pensión percibida hasta ahora.

Para compensar durezas sociales, especialmente para las personas que perciben pensiones bajas, así como para estudiantes, se crearán las correspondientes normas jurídicas en la RDA. La RDA adoptará tales normas en el marco de su propia responsabilidad financiera y teniendo en cuenta su situación financiera global.

En lo que respecta a las modalidades de cambio per cápita, nos pusimos de acuerdo sobre el ya conocido escalonamiento según la edad de vida respectiva.

Señoras y señores, como todos Vds. han podido hacer constar, hemos previsto un arreglo más favorable para las personas mayores que para los demás grupos de edad. Formo parte de aquellos que han apoyado decididamente este arreglo, así como el trato especialmente favorable del tema de las pensiones. Creo que esto corresponde a nuestra responsabilidad común con respecto a la generación de los mayores que después de la Segunda Guerra Mundial tuvieron que soportar además la carga de 40 años de dictadura socialista y de mala gestión económica. Esta generación se merece de manera especial nuestro respeto, nuestra simpatía y nuestro respaldo.

Señoras y señores, con estos acuerdos el tratado sobre la unión monetaria, económica y social ha tomado cuerpo en un sector funda- 
mental. Ahora nuestros compatriotas en la RDA pueden apreciar lo que la introducción del marco occidental significa para ellos en cada caso particular. Al hacerlo así constatarán que el Gobierno Federal ha cumplido con lo que había prometido.

Actualmente se están negociando otros detalles del tratado y para mí es cosa sumamente natural que el cambio de la moneda esté indisolublemente unido al acuerdo global sobre el tratado.

Habrá que negociar todavía algunos puntos importantes, por ejemplo también los aspectos particulares de las relaciones económicas exteriores de la RDA con los países miembros del Consejo de Asistencia Económica Mutua, ante todo con la Unión Soviética. Se trata del problema de cómo puede configurarse el necesario ajuste estructural de las empresas en la RDA bajo puntos de vista económicos y sociales. También quedan por aclarar aspectos difíciles en el sector agricola de la RDA. Esto se refiere también a la inclusión de la agricultura de la RDA en la política agrícola europea, que, en vista de la situación real que se presenta en estos momentos, desde luego sólo puede realizarse de forma escalonada.

Permítanme decir en este lugar algunas palabras con respecto al procedimiento de fijación de los precios agrarios de este año. Las negociaciones han sido especialmente difíciles porque hasta ahora ha sido insuficiente la disminución de la producción de cereales en Europa. A este respecto, los agricultores de la República Federal de Alemania han hecho justicia a su corresponsabilidad. Ellos han abandonado más superficies agrícolas que los agricultores de cualquier otro Estado miembro. Partimos de que la Comunidad Europea tomará próximamente las medidas concretas anunciadas. Debe producirse una descarga del mercado europeo de cereales. Las explotaciones familiares que se dedican a la producción de cereales son las que necesitan ante todo una perspectiva para el futuro.

Señoras y señores, en nuestras conversaciones con el Gobierno de la RDA debemos discutir también de qué manera puede crearse el equilibrio entre las prestaciones sociales, por una parte, y la capacidad de rendimiento económico, por otra, al realizarse la unión social. Éste es uno de los temas de suma importancia.

Además, el Gobierno de la RDA debe determinar cómo configurará, en relación con el cambio de la moneda, los arreglos previstos contra abusos. Creo que para la buena aceptación de todos los arreglos es de suma importancia que se haga todo lo posible $-y$ tampoco en este aspecto tenemos ningún motivo para dudar de la buena voluntad del Go- 
bierno de la RDA - para tomar medidas contra especuladores y aquellas personas que dispongan de fondos ilegalmente adquiridos. A este propósito hemos presentado sugerencias y deberiamos emprender esfuerzos conjuntos en este sentido.

Reitero una vez más: la meta común consiste en mejorar a fondo y a la mayor brevedad posible la situación económica de las personas humanas entre el Elba y el Oder. Para ello los inversores necesitan la suficiente seguridad y calculabilidad para sus actividades económicas, independientemente de si proceden de la RDA, la República Federal de Alemania o de otros países. Estoy convencido de que podemos llegar sin dilaciones a los acuerdos necesarios con la RDA. Lo que hace falta ante todo es la rápida introducción de la economía social del mercado, la estabilidad de la moneda, la solidez de los presupuestos estatales, tanto en la RDA como aquí, y un equilibrio social en lo tocante a cada una de las medidas adoptadas.

No cerramos los ojos ante el hecho de que tenemos que hacer considerables esfuerzos, esfuerzos que pueden constituir al mismo tiempo sacrificios. Estos esfuerzos, pensando por ejemplo en los presupuestos estatales, tienen que hacerse ante todo también en la RDA. Forma parte de ello la posibilidad de recurrir al llamado patrimonio del pueblo. Pero este desafío se refiere naturalmente también a los presupuestos públicos aquí en la República Federal de Alemania, a nivel de la Federación, de los Estados federados y de los municipios.

Sin embargo, sería completamente erróneo enfocar en este contexto exclusivamente el aspecto de los gastos del proceso de unificación, por muy importante que sea tal enfoque; porque todo respaldo a la transición de la RDA a la economía social de mercado constituye al mismo tiempo una inversión en nuestras propias posibilidades de crecimiento, asi como en las de la Alemania unida.

La verdad es que todos se beneficiarán de la futura dinámica económica en la RDA, y no en último término los empleados y las empresas aquí en la República Federal de Alemania. Ahora se trata de alentar a nuestros compatriotas en su salida hacia un futuro mejor. Pero alentarles quiere decir al mismo tiempo que no haremos nada que pudiera reducir las perspectivas de nuestra propia economía. Por eso repito una vez más: Nosotros en la coalición no vemos ningún motivo para aumentar los impuestos con miras a la financiación de la unidad alemana.

Nuestra experiencia, confirmada hace poco por el Instituto Alemán de Investigaciones Económicas, es totalmente distinta: la receta más prometedora de éxito para una economía floreciente consiste en promover 
la disposición al rendimiento y la iniciativa individual. Éste es también el motivo -fácilmente perceptible- de los crecientes ingresos fiscales de la Federación, de los Estados Federados y de los municipios. Cuando se trata de obtener más ingresos fiscales, una economía floreciente es siempre mejor que un aumento de los impuestos que disuade del rendimiento.

En cuanto al problema de la financiación - como en todos los demás puntos relacionados con el tema de la unidad alemana-, como jefe de Gobierno tengo el mayor interés en la conversación franca e intensa con todos los participantes: La semana entrante celebraremos una primera conferencia con los presidentes de los Estados federados. Tendremos que hablar con las confederaciones comunales sobre este tema. Quisiera volver a corroborar en público lo que se ha dicho en muchas conversaciones: Es mi deseo urgente que en la comisión parlamentaria para la unidad alemana, que se constituirá mañana, se realice la comunicación más estrecha posible, la conversación más abierta posible con todos los Ministerios del Gobierno Federal. Lo mismo vale para las relaciones entre los diversos Ministerios y las comisiones especializadas del Bundestag.

Señoras y señores, con respecto a algunos temores realmente existentes, pero también con referencia a otros temores producidos por campañas de envidia, quisiera preguntar sencillamente: ¿cuándo es que los alemanes quieren solucionar económicamente el problema de la unidad alemana, sino ahora, en estos momentos, cuando la economía alemana se presenta ante todo el mundo en un estado tan excelente? Estamos en el octavo año del auge económico, que es al mismo tiempo el período de prosperidad más largo e ininterrumpido en la historia de la República Federal de Alemania. Por eso opino que nos conviene el realismo, y no nos convienen ni pesimismo ni pusilanimidad. Nos hacen falta valor, fantasía y la disposición a cooperar con energía a la realización de las tareas que tenemos por delante, tanto en la RDA como aquí en la República Federal de Alemania. Tenemos buenas perspectivas para superar las dificultades. Las oportunidades que conlleva la unidad de Alemania se desenvolverán en provecho de las personas humanas en la República Federal de Alemania, en la RDA y en Europa.

Apelo en este momento a todas las partes a que se aúnen ahora en solidaridad nacional. La tarea es inmensa, pero merece la pena. A finales de un siglo que ha colmado de tantos sufrimientos y horrores, en nombre alemán, a las personas humanas, se nos ofrece a nosotros los alemanes una única oportunidad, la oportunidad de "consumar en libre autodeterminación la unidad y libertad de Alemania" y "servir a la paz del mundo, integrado en una Europa unidan. Éstas son las palabras de nuestra Constitución, nuestra Ley Fundamental. Nosotros estamos dispuestos a hacer esta aportación. 